\title{
As operações urbanas consorciadas como instrumento de promoção do meio ambiente urbano saudável
}

\section{SYNDICATED URBAN OPERATIONS AS A TOOL FOR PROMOTING HEALTHY URBAN ENVIRONMENT}

\author{
Thaís Bernardes Maganhini * \\ Pablo Oliveira Martins **
}

Resumo: A Constituição Federal em seu artigo 182 estabelece que as ações de política urbana, de competência executória dos Municípios, terão como objetivo assegurar o cumprimento das funções sociais da cidade, atendendo as necessidades da comunidade em relação aos seus direitos básicos e garantindo o bem-estar dos seus habitantes. Hoje, o entendimento de bemestar perpassa pelas melhorias infraestruturais e sociais e pela proteção ambiental. Nesse sentido, as operações urbanas consorciadas, instrumento previsto no Estatuto da Cidade (Lei 10.257, 10 de julho de 2001), permitem que a sociedade civil atue em conjunto com o Poder Municipal equacionando o desenvolvimento urbano com o direito ao meio ambiente equilibrado, enfrentando os problemas diretamente e promovendo a cidadania.

Palavras-Chave: Política Urbana; Operação Urbana Consorciada; Meio Ambiente Urbano; e Atuação Participativa.

Abstract: The article 182 of Federal Constitution of Brazil establishes that urban policy, a municipalities execution competence, aims to observance of social functions of the city, ensuring the population need's and the basic rights of citizens,

* Thaís Bernardes Maganhini: especially the well-being of the local residents. Today, the urban well-being includes the social and the infrastructure improvements and environment protection. Therefore, the Federal Law n. 10.257, July $10^{\text {th }} 2001$, provides the consociate urban operation as the instrument that allows the participative and joint action between the local government and the citizens, equating the urban development with the right to an ecologically balanced environment, facing the problems directly and promoting the citizenship.

Keywords: Urban Policy; Consociate Urban Operation; Urban Environment; and Participative Action. 


\section{INTRODUÇÃO}

A cidade é o centro das relações sociais, nela os homens têm a possibilidade de alcançar os estados físicos, sociais e morais que lhes são necessários para a vivência. Contudo, o crescimento populacional e o desenvolvimento econômico das últimas décadas, baseados no consumo excessivo dos recursos naturais, geraram consequências danosas, não apenas para o meio natural, como também para as áreas urbanas.

Para José Afonso da Silva (1997, p. 151) é no meio ambiente urbano que a degradação ambiental primeiro repercute como se pode notar nas várias formas de poluição que atingem as cidades: poluição sonora, visual, atmosférica, das águas, do solo, entre outras. Em busca de melhorias na qualidade de vida dos habitantes, a Constituição Federal, em seu art. 182, apresenta os caminhos pelos quais as políticas urbanas devem seguir, tendo como base, ainda, o art. 225, que estabelece o direito de todos ao meio ambiente ecologicamente equilibrado, preservando-o para a atual, e para as futuras gerações.

São esses os parâmetros de desenvolvimento ambiental que, na atualidade, deverão balizar as ações urbanísticas, e que serão efetivadas a partir dos instrumentos elencados no Estatuto da Cidade (Lei 10.257, de 10 de julho de 2001).

O Estatuto da Cidade veio regulamentar o crescimento das cidades, criando instrumentos de política urbana que atendam aos aspectos sociais, ambientais e econômicos de desenvolvimento. Dentre esses instrumentos, destaca-se a Operação Urbana Consorciada, como meio apto a garantir uma melhor qualidade de vida aos habitantes da cidade, através da atuação conjunta entre o Poder Público, proprietários, moradores, usuários permanentes e investidores privados para alcançar, em áreas determinadas pelo seu plano de operação, transformações urbanísticas estruturais, melhorias sociais e valorização ambiental.

Nesta linha, o artigo analisará, através do método dedutivo, o instituto da Operação Urbana Consorciada e sua importância para o desenvolvimento do meio ambiente urbano, tendo como ponto de partida as prescrições e os direitos assegurados na Constituição Federal, e como destino, a efetivação das normas constitucionais por meio dos institutos urbanísticos elencados no Estatuto da Cidade.

A parte inicial apresenta a forma como a política urbana é tratada na Constituição Federal; posteriormente, são expostas as balizas constitucionais do desenvolvimento do meio ambiente urbano; o terceiro tópico apresenta os 
elementos que compõe o instituto da Operação Urbana Consorciada. Por fim, no quarto tópico, focaliza-se a ação participativa, ou seja, a proximidade entre governo e população (de forma direta ou indireta), atuando conjuntamente em prol da valorização ambiental nas cidades.

\section{DA POLÍTICA URBANA NA CONSTITUIÇÃO DE 1988}

A Constituição Federal de 1988 é um marco jurídico na regulação das questões de direito urbanístico no Brasil; nascida em tempos que fervilhavam problemas internos, de ordem política (redemocratização) e econômica (inflação). O contexto que movimentou os anseios democráticos daquela constituinte caracterizou-se, desde a década de 1960, pela busca de um crescimento econômico necessário a um Estado de grandes dimensões territoriais, mas que não possuía protagonismo no cenário mundial. Essa expansão na economia do Brasil, com efeitos quase que anabólicos, mostrou a realidade do País que insiste em cometer os mesmos erros de planejamento e gestão desde a sua colonização a mais de 500 anos.

O conceito de desenvolvimento exaltado no último século mostrou-se como sinônimo de crescimento econômico, sendo a pragmática dos números vetor de um aparente estado de bem-estar. Todavia, a atual acepção do termo desenvolvimento não se satisfaz apenas com indiciadores econômicos. Essa visão liberal gradualmente foi ultrapassada pelos paradigmas emergentes do Estado Social de Direito, que também insuficiente, adquiriu hoje a feição de Estado Democrático de Direito, uma conjuntura que busca garantir o crescimento econômico pautado pela promoção dos direitos fundamentais. Para tanto requer a revisão da lógica liberal onde a desigualdade entre as classes sociais cresce proporcionalmente ao crescimento dos lucros, e a da lógica social, marcada por um intervencionismo estatal desmedido.

Como síntese do atual estágio desse processo, Marcelo Dias Varella (2004, p. 40) define que 'em uma lógica mais política e social, o desenvolvimento é medido pela expansão de liberdades, como o acesso à saúde e à educação, à proteção do meio ambiente e à democracia”, o que, é claro, não é possível sem uma economia saudável.

As cidades brasileiras, exemplos dos problemas de planejamento e gestão das políticas públicas, crescem (no sentido liberal) em áreas inadequadas, sem observar as regras de proteção ambiental e social, não sendo capazes de suprir as necessidades básicas de seus habitantes diante do número cada vez maior de consumidores de recursos naturais e artificiais, que em contrapartida, 
produzem mais resíduos e poluentes, constroem mais edifícios, transformam o ambiente de acordo com suas necessidades. Frente a esse quadro, o Poder Público não pode quedar-se omisso, devendo cumprir a sua função de ordenador e executor das relações de interesse comum do povo.

Para disciplinar os assuntos que envolvem o desenvolvimento e a organização das cidades, a Constituição de 1988 reservou um capítulo especial dispondo sobre a Política Urbana, o Capítulo II, do Título VII (Da Ordem Econômica e Financeira). Destaca-se, que, não por coincidência, a diretrizes constitucionais de organização das áreas urbanas estão inseridas no título da Constituição que versa sobre a ordem econômica, podendo ser interpretado, tal disposição da estrutura normativa, como um direcionamento inicial das funções urbanísticas para o desenvolvimento da economia citadina, considerando que há um elo indissociável entre desenvolvimento e economia. Todavia, essa visão ainda emerge dos resquícios do pensamento liberal.

Mais além, o art. 182 da Constituição Federal institui a política de desenvolvimento urbano, e explicita seus objetivos que são: realizar as funções sociais da cidade em sua plenitude, e garantir o bem-estar de seus habitantes. Partindo de tais objetivos, nota-se que o foco das políticas urbanísticas, à primeira vista, com o viés econômico, volta-se, cada vez mais, para a qualidade de vida no meio ambiental urbano, trazendo a lume questões que adquiriram relevo internacional a partir dos anos de 1970, como o meio ambiente equilibrado e o desenvolvimento sustentável.

Dispõe ainda, que a União disciplinará as normas gerais para o desenvolvimento urbano, inclusive quanto à habitação, ao saneamento básico, e aos transportes urbanos, conforme o art. 21, XX da CF. Mas, os Estados e o Distrito Federal também poderão legislar sobre matérias de direito urbanístico, concorrentemente com a União, e de forma suplementar, quando os assuntos abarcarem regiões intermunicipais, e forem de interesse regional.

Conquanto, no que versa sobre o objeto do presente trabalho - as operações urbanas consorciadas - deve-se destacar a qual ente a constituição incumbiu a importante e, ao mesmo tempo, complexa tarefa de executar as ações de política urbana. Este dever foi posto nas mãos do Poder Público Municipal, e por uma razão simples, ninguém mais do que o governo do Município conhece as necessidades e os problemas das regiões urbanas compreendidas em seu território, além do que, se não apenas a regulação, mas também, a execução das políticas estivesse a cargo da União ou dos Estados, o gasto com planejamento e o dispêndio de recursos seria maior. Como muitos gostam de afirmar, o homem não reside na União ou no Estado, e sim nos Municípios. 
Nesse aspecto, José Afonso da Silva, em seu Curso de Direito Constitucional Positivo, tece comentário importante ao criticar essa monopolização municipal da execução do desenvolvimento urbano. Assim afirma:

Mas essa política de desenvolvimento urbano fica bastante empobrecida e talvez não terá condições de implementar os objetivos importantes a ela assinados pelo art. 182, se não vincular a uma política mais ampla que leve em conta também dimensões interurbanas, como parte integrante de uma política de desenvolvimento econômico e social que ultrapassa o nível estritamente municipal. (SILVA, 2000, p. 791).

A essa visão do emitente constitucionalista brasileiro, deve ser acrescentado outra face de atuação, ainda utilizada de forma incipiente pelos órgãos de planejamento urbano, que também enriquecerá os meios de ação municipais, possibilitando a maior efetividade dos objetivos almejados. Trata-se das operações urbanas consorciadas, prevista na lei 10.257/2001, que abrangem não as dimensões interurbanas, também necessárias, mas as dimensões intraurbanas, ou microrregionais, pois seu campo de atuação se faz presente nos bairros, nas comunidades, nas regiões da cidade, e requer a parceria entre os órgãos municipais e os entes da sociedade civil.

Analisando os institutos presentes no texto constitucional, observa-se que administrar uma cidade requer a feitura de um conjunto de ações com parâmetros e objetivos norteadores. O termo política pública traz a feição de um ' conjunto de atos unificados por um fio condutor que os une ao objetivo comum de empreender ou prosseguir um dado projeto governamental para o País” (MELLO; 2011; P. 821). Dessa forma, a política urbana expressa ações que o constituinte de 1988 definiu como necessárias para a Administração Pública executar no que concerne aos problemas incidentes nas áreas urbanas.

Os caminhos que essas ações urbanísticas devem seguir apresentam dois objetivos principais, que são garantir o pleno desenvolvimento das funções sociais da cidade, e o bem-estar dos seus habitantes. Nesse ínterim, o Governo responsável pela administração da cidade elaborará projetos de gestão, e os

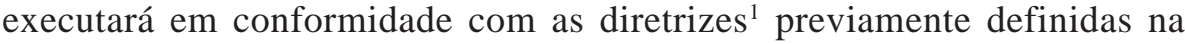
Constituição e em outros instrumentos legais.

$\mathrm{O}$ art. 182, caput, estabelece que tais diretrizes sejam fixadas em lei específica, a lei n. 10.257, que foi promulgada em 10.07.2001, e se autodenominou

\footnotetext{
$\overline{{ }^{1} \text { Na definição de Odete Medauar }}$ (2004, p. 20), diretrizes são preceitos norteadores da efetivação de uma política pública.
} 
de Estatuto da Cidade. O estatuto tem como função regulamentar a execução da política urbana, através de institutos especificados em seus artigos.

Outro instrumento básico que os municípios, com mais de 20 mil habitantes, entre outros com algumas particularidades², deverão observar para o desenvolvimento da expansão urbana, é o Plano Diretor, previsto no $\S 1^{\circ}$ do art. 182 da CF/88. Assim, observa-se que, em matéria de regulação da política urbana, os municípios possuem instrumentos variados para guiarem sua atuação.

Analisando o Estatuto da Cidade especificamente, em seu art. $1^{\circ}$, parágrafo único, este define que o seu objeto de regulação é o uso da propriedade urbana em prol do bem coletivo, da segurança, do bem-estar dos habitantes, e do equilíbrio ambiental. $\mathrm{O}$ art. $2^{\circ}$, por sua vez, elenca as diretrizes gerais dos planos de ação urbanísticos, a exemplo do planejamento, da gestão democrática, da preservação e valorização ambiental, entre outras. Assim, os artigos $1^{\circ}$ e $2^{\circ}$ estabelecem de que forma os instrumentos da política urbana, previstos no art. $4^{\circ}$ do mesmo Estatuto, serão guiados em busca dos objetivos constitucionais.

Todos esses dispositivos regulamentadores têm com destinatários imediatos os políticos, administradores e responsáveis em geral pela garantia de que o texto constitucional se fará presente na busca por uma melhor qualidade de vida dos cidadãos. Os destinatários mediatos são os próprios viventes das cidades que sentirão as melhorias no dia-a-dia.

O Estatuto da Cidade também inovou em muitos de seus institutos ao aproximar o governo de seus governados, ou seja, ao dar à participação da comunidade na elaboração e execução das ações urbanísticas, o caráter de legitimadora da intervenção estatal. Portanto, a atuação dos cidadãos adquiriu importância fundamental na ordenação das cidades, em busca do equilíbrio entre os interesses do Poder Público, e das grandes corporações, e as necessidades da população.

Nesse sentido, conforme o art. $2^{\circ}$, XIII do Estatuto da Cidade, é diretriz social da política urbana a prévia audiência do Poder Público Municipal e da população interessada no processo de implantação de empreendimentos e/ou atividades com o potencial negativo de interferência no meio ambiente natural e urbano, no conforto e segurança dos habitantes.

Também é dever dos Poderes Legislativo e Executivo municipais garantir a promoção de audiências e debates com a participação da população e associações representativas dos segmentos da comunidade, dar publicidade e permitir o acesso a qualquer interessado dos documentos e informações

${ }^{2}$ Art. 41 da Lei 10.257/2001. 
produzidos no processo de elaboração e execução do plano diretor (art. 39, §4 da Lei 10.257/2001).

\section{DAS DIRETRIZES DA POLÍTICA URBANA E O MEIO AMBIENTE EQUILIBRADO}

Como já observado, assegurar o desenvolvimento das funções sociais da cidade e garantir o bem-estar dos seus habitantes são objetivos das ações de política urbana preconizadas na Constituição Federal e no Estatuto da Cidade. Entretanto, Carvalho Filho (2013, p. 19) afirma que o bem-estar dos habitantes já estaria abrangido pelo dever de assegurar o desenvolvimento das funções sociais da cidade, pois a consequência lógica da realização de tais funções relacionadas à infraestrutura, à educação, à saúde, ao transporte público, à segurança, seria a satisfação dos interesses individuais, e coletivos, assim, garantindo o bem-estar daqueles que ali residem. Poder-se-ia, então, considerar certo excesso, por parte do legislador, na elaboração do mandamento constitucional?

Não se deve entender como excesso, mas sim, como uma clara intenção do legislador de enfatizar essas disposições de preservação do meio ambiente, merecendo planejamento e fiscalização mais acentuados.

Ademais, também se observa a estreita relação entre o bem-estar e a qualidade de vida, quanto maior for esta, o bem-estar dos moradores será maior; mas a qualidade de vida perpassa por aspectos outros do que os meramente econômicos, ela requer, principalmente, a existência de uma ambiência adequada para o convívio social, que permita o viver saudável, ou seja, é necessária a manutenção de um equilíbrio entre as inúmeras atividades desenvolvidas na urbe e o meio-ambiente que a envolve.

O art. 225 da Constituição Federal prevê que todos têm direito a viver em um ambiente ecologicamente equilibrado, o que é essencial à qualidade de vida das pessoas. Logo, as ações de políticas municipais, voltadas ao bem-estar dos habitantes da cidade, não podem olvidar da proteção ao meio ambiente urbano.

Importa destacar que o atual entendimento acerca do conceito de meio ambiente compreende a junção de três aspectos: o natural, ou físico, constituído pela interação entre os elementos naturais e os seres vivos; o cultural, integrado pelo patrimônio histórico, artístico, arqueológico, paisagístico, turísticos; e o artificial, mais afeto ao direito urbanístico, que é formando pelos edifícios e os equipamentos urbanos (praças, ruas, áreas verdes, entre outros). 
Assim, José Afonso da Silva (1998, p. 2) define o meio ambiente como: a interação do conjunto de elementos naturais, artificiais e culturais que propiciem o desenvolvimento equilibrado da vida em todas as suas formas.

O eminente doutrinador ainda destaca que a integração do conceito de meio ambiente advém da tendência existente do meio natural e do meio cultural convergirem para a formação do meio ambiente urbano. Nessa relação dois interesses se sobressaem nas discussões sobre a qualidade do meio ambiente urbano: a qualidade do meio ambiente natural, do ar, da água, das florestas; e o desenvolvimento das comunidades (SILVA, 1999, p. 4). Assim, a qualidade de vida dos habitantes da cidade estará condicionada a relação entre os meios naturais e as obras do homem, ou, sua intervenção na natureza.

Considerando que a qualidade do meio ambiente também se encontra inserida nos objetivos da Política Urbana, as diretrizes instituídas pela União (art. 21, XX da CF), as políticas de desenvolvimento elaboradas, e as ações do Poder Municipal na execução de tais políticas, devem buscar a construção e a ordenação de um meio ambiente urbano equilibrado e saudável, no qual todos os elementos da vida sejam eles naturais, artificiais, ou culturais, coexistam e se relacionem ordenadamente, respeitando às diferenças de preservação e cuidado necessárias para cada setor.

Seguindo esse raciocínio fica claro que 'a qualidade de vida do meio ambiente urbano constitui mesmo um ponto de convergência da qualidade do meio ambiente natural (água, ar e outros recursos naturais) e da qualidade do meio ambiente artificial (histórico-cultural)”' (SILVA, 1998, p. 151).

No que toca aos meios para alcançar esse equilíbrio preconizado pela Constituição, cumpre, primeiramente, elaborar um plano estratégico de atuação, tendo em vista, a complexidade das relações urbanas atuais, que promove constantes conflitos entre grupos que querem o desenvolvimento sob a ótica liberal (ou neoliberal), e aqueles promotores da preservação do patrimônio natural e histórico-cultural.

O planejamento das ações é fundamental para a conciliação entre todos os setores da sociedade, e para a consecução dos objetivos traçados, assim está previsto no art. $2^{\circ}$, IV, do Estatuto da Cidade, que o planejamento do desenvolvimento das cidades será elaborado de modo a evitar e corrigir as distorções do crescimento urbano e seus efeitos negativos sobre o meio ambiente. Não se tratando de um planejamento apenas técnico, mas sim, lastreado juridicamente, para que o administrador siga o caminho desenhado pelo direito positivo em respeito ao princípio constitucional da legalidade. 
Esse planejamento é possível através dos planos urbanos que poderão ser elaborados pelos entes federais, estaduais ou municipais, a depender da amplitude das ações (se locais, regionais ou nacionais), com fundamento nas diretrizes previstas na Constituição e na lei, sendo voltado para o desenvolvimento das cidades, para a distribuição espacial da população, e para as atividades econômicas do Município e da área sobre influência.

É claro que o viés econômico está diretamente ligado e exerce influência considerável na elaboração e execução dos planos urbanos, principalmente em relação às particularidades econômicas de cada ente municipal. Nesse contexto, cabe aos Municípios o zoneamento dos setores da sua economia, de acordo com as várias regiões da cidade, para equacionar as necessidades de desenvolvimento da cidade (a partir do comércio, da indústria, do consumo, dos serviços) com a proteção do meio ambiente, prevista no art. 225 da CF. Assim, afirma Moreira e Araújo que:

Em um Estado Democrático de Direito como o nosso, que se preocupa não somente com a aplicação formal, bem como a material do princípio da igualdade, o desenvolvimento econômico não deve se desvincular da inclusão social e da harmonia ambiental. (2007, p. 10).

Em síntese, a diretriz do planejamento, observa Carvalho Filho (2013, p. 36), se apresenta de duas formas: a preventiva; e a repressiva. A primeira seria a organização do espaço urbano de maneira que atenda às suas funções essenciais, e a segunda, vem para corrigir a desorganização urbana que traz prejuízos, quase irreversíveis, ao meio ambiente.

O plano diretor, como instrumento basilar das ações urbanísticas municipais, é parte integrante do processo de planejamento e deverá incorporar tais diretrizes previstas no Estatuto da Cidade.

Todavia, o planejamento é apenas o primeiro passo, onde se estabelecem os caminhos que serão seguidos, a forma com que os objetivos serão alcançados, os agentes que atuarão, o local que será atingido pelas ações. O Estatuto da Cidade, Lei 10.257/2001, elencou instrumentos de política urbana através dos quais será possível aplicar os objetivos traçados nos planos urbanos.

\section{DAS OPERAÇÕES URBANAS CONSORCIADAS}

Dentre os instrumentos previstos no artigo $4^{\circ}$ da Lei 10.257/2001, encontram-se as operações urbanas consorciadas, expressas no inciso V, alínea 
p, concebidas como um instituto jurídico e político, autorizado por lei municipal específica, e em consonância com as diretrizes do plano diretor municipal.

Observa Carvalho Filho (2013, p. 274) que as operações urbanas consorciadas revelam-se como mais um instrumento advindo do modelo de regime de parceria, de aplicação na seara do direito administrativo, caracterizada pelo desenvolvimento, execução e gestão das políticas públicas a partir da colaboração entre a administração e os administrados.

Esse modelo de execução das políticas públicas fundamenta-se no entendimento de que os entes, sejam eles públicos ou privados, não conseguem atingir, em sua plenitude, os objetivos comuns colacionados na Constituição Federal atuando de forma isolada. A ação dos entes em parceria amplia o campo de atuação e gera resultados mais satisfatórios. Ou, parte-se da "premissa de que haverá, ao final do processo, uma melhoria da capacidade do Estado de atender às demandas sociais” (ROCHA apud MELLO, 2011, p. 223).

As operações urbanas consorciadas, desse modo, fazem parte de um conjunto de atividades existentes no Brasil que podem ser realizadas pelo setor público e pelo setor privado, de forma conjunta, atendendo eficientemente a todas as partes dessa relação.

No campo do direito administrativo, considera-se entidade do terceiro setor, aqueles particulares que adquirem uma qualificação específica em razão das atividades por eles executadas, quase sempre, direcionadas à educação, à saúde, à proteção ambiental, à assistência social.

Tais entidades, hoje, podem ser denominadas de Organizações Sociais $(\mathrm{OS})^{3}$ ou Organizações da Sociedade Civil de Interesse Público (OSCIP), assim como outras que poderão ser qualificadas pelo Poder Público, a depender da necessidade da administração e da coletividade.

Os particulares que executam atividades de interesse público, no caso das OSCIP, as realizam a partir da elaboração de um Termo de Parceria com o Poder Público. Devido a essa atuação conjunta na prestação de atividades úteis à sociedade, assemelha-se, em certos aspectos, ao instituto jurídico-político dos consórcios, que, para José dos Santos Carvalho Filho, trata-se de "instrumento em que pessoas públicas ou privadas ajustam direitos e obrigações com o objetivo de alcançar metas de interesse recíproco” (2013, p. 228). Ou, como bem expressa Celso Antônio Bandeira de Mello, seriam contratos em que as partes se compõem pela comunidade dos interesses (2011, p. 671).

\footnotetext{
${ }^{3}$ Lei 9.637, de 15 de maio de 1998.

${ }^{4}$ Lei 9.790, de 23 de março de 1999.
} 
Seguindo, pois, um modelo típico do direito administrativo, o Estatuto da Cidade, ao estabelecer vários instrumentos para a consecução das diretrizes traçadas nos art. 182 e 183 da CF/88, também previu situações em que a administração e os administrados poderiam e, deveriam agir em cooperação de esforços. Nesse sentido, o art. 32, $\S 1^{\circ}$ do Estatuto define o que vem a ser 0 instituto em estudo, dispondo que:

$\S 1^{\circ}$ Considera-se operação urbana consorciada o conjunto de intervenções e medidas coordenadas pelo Poder Público municipal, com a participação dos proprietários, moradores, usuários permanentes e investidores privados, com o objetivo de alcançar em uma área transformações urbanísticas estruturais, melhorias sociais e a valorização ambiental. (art. 32, §1º da Lei 10.257/2001).

Segundo Moreira e Araújo (2007, p. 4), o termo operação urbana consorciada pode ser compreendido em três sentidos: a) no sentido genérico, como qualquer intervenção pública urbanizadora; b) no sentido estrito, como a aplicação de instrumentos específicos de urbanização; c) ou como um tipo especial de intervenção urbanística. Essa última forma de compreensão se deve a especialidade das operações no sentido de envolverem, como informa as autoras, alternativa ou simultaneamente a combinação de capital público e privado para as intervenções previstas no art. 32 do Estatuto da Cidade.

No sentido do que prevê a Constituição Federal, incumbindo o Município do dever de executar a política de desenvolvimento urbano, a este também é dado o papel de coordenador das medidas consorciadas em ações urbanísticas.

Vê-se que não haverá mera transferência de direitos e obrigações aos particulares e sujeitos do consórcio, mas atuação direta dos órgãos Municipais na coordenação das medidas interventivas delineadas pelo plano de operação.

Para a aplicação do referido instrumento é necessário edição de lei municipal específica, nos termos do que assinala o caput do art. 32, determinando a área objeto da operação. A delimitação da área através de lei é fundamental, pois as transformações urbanísticas estruturais para serem alcançadas demandarão que o Município intervenha no direito de propriedade, trazendo, muitas vezes, ônus aos particulares em prol de melhorias para um número maior de habitantes.

Por seu caráter interventivo, tais ações terão como parâmetro as diretrizes estabelecidas pelo plano diretor, no que tange ao uso e ocupação do solo de cada zona da cidade. 
Logo, não se poderá estabelecer uma operação consorciada cujo objetivo seja alterar o coeficiente de construção de uma determinada região da cidade a qual o plano diretor não tenha previsto tal possibilidade, ou não a permita expressamente. Pelo contrário, na própria elaboração e revisão do plano diretor será necessário que sejam apontadas, nas diversas áreas de zoneamento, em quais se admitirá as operações urbanas (CARVALHO FILHO, 2013, p. 280).

Na mesma linha, o art. 33, I, do Estatuto da Cidade, impõe que:

Da lei específica que aprovar a operação urbana consorciada constará o plano de operação urbana consorciada, contendo, no mínimo, I - a definição da área a ser atingida, II - o programa básico de ocupação da área, III - o programa de atendimento econômico e social para a população diretamente afetada pela operação, IV - a finalidade da operação, V - o estudo prévio de impacto de vizinhança, VI - a contrapartida a ser exigida dos particulares pelos benefícios adquiridos, e VII - a forma de controle da operação.

Segundo Carvalho Filho (2013, p. 280), essas definições são indispensáveis, pois indicarão os destinatários das operações, e o objetivo do Município em implementá-las. Sendo um dos pilares do direito público o princípio da legalidade, o Estado não poderá impor medidas restritivas aos direitos individuais se não houver lei autorizando que o faça.

O próprio Estatuto da Cidade traz as medidas que poderão constar no plano de operação urbana, quais sejam: a modificação de índices e características de parcelamento, uso e ocupação do solo e do subsolo; ou a regularização de construções, reformas ou ampliações executadas em desacordo com a legislação vigente.

Este rol, entretanto, não é taxativo, podem ser previstas outras medidas desde que tenham como finalidade obter melhorias estruturais, sociais e ambientais no espaço urbano.

Não obstante a obrigação legal do Município, o consórcio pressupõe cooperação, dessa forma, outros entes mostram-se importantes para a concretização das ações, são eles: os proprietários, os moradores, os usuários permanentes, os investidores privados, em suma, entes da sociedade civil que, de alguma maneira, têm interesse na melhor execução das políticas urbanas, ou por serem afetados diretamente, ou por visualizarem benefícios futuros, ou por terem tal vertente de atuação como finalidade de sua existência, a exemplo de algumas OSCIP $^{5}$ e OS.

\footnotetext{
${ }^{5}$ Instituto AQCUA, criado em 1999 em Ribeirão Pires - SP, atua em parceria com outros órgãos públicos e privados nas áreas de saúde, meio ambiente, esporte, educação, urbanismo e cultura buscando melhorias na qualidade vida urbana. http://www.institutoacqua.org.br/.
} 
Os participantes das operações urbanas consorciadas dividem-se, então, em dois grupos: a) agentes do setor público; b) agentes do setor privado. $\mathrm{O}$ setor público tem como representante o Município, o setor privado, aqueles grupos mencionados pelo $\S 1^{\circ}$ do art. 32 do Estatuto da Cidade.

Para Carvalho Filho (2013, p. 227), apesar da função principal de execução e coordenação ser dos Municípios, isso não impede que os Estados ou a União também atuem em parceria com os entes da sociedade civil, em casos que produzam efeitos de interesse regional ou nacional. Pois, quando se fala em garantia dos objetivos constitucionais, incluindo os de ordem urbanística e ambiental, não se pode ter uma visão restritiva, e sim, ampliá-la para a sua máxima efetividade.

Quanto aos agentes privados, consideram-se os proprietários os maiores beneficiados por tal instituto, afinal, sendo titulares do direito de propriedade, as transformações que venham a ordenar a disposição urbana da área delimitada, possibilitarão um ganho em relação aos índices de uso do solo e subsolo, a regularização das áreas construídas, e até, a valorização imobiliária.

Nesse sentido, Hely Lopes Meirelles (2005, p. 171) destaca as operações urbanas consorciadas como um efetivo instrumento de regularização fundiária que vem assegurar o direito à moradia, previsto no artigo $6^{\circ}$ da Constituição Federal de 1988.

Outro grupo a ser afetado são os moradores, entes fundamentais na construção de uma comunidade participativa, em que os processos políticosdecisórios pautam-se por uma cidadania republicana e menos passiva (BONIZZATO, 2005, p. 161). Trata-se daqueles residentes do local selecionado para a aplicação das medidas consorciadas, porém, não necessariamente, proprietários dos imóveis beneficiados, a exemplo dos locatários de imóveis, dos comodatários, enfiteutas, usuários herdeiros, sucessores, etc. Em síntese, todos aqueles que residem na região afetada sem serem proprietários.

Os usuários permanentes são aqueles que fazem usufruto frequente do local, não sendo, necessariamente, proprietários ou moradores. Como exemplo de usuários permanentes há os trabalhadores, os servidores públicos, os comerciantes, os estudantes, os prestadores de serviço, ou seja, os que usam a área para determinada finalidade que não habitacional, e são atingidos pelas intervenções municipais.

Por último, os investidores privados também podem ser colaboradores das operações urbanas consorciadas, sem que o objetivo seja meramente a obtenção de lucros, desde que o interesse público, na busca de melhorias de cunho urbanístico para região, prevaleça e seja alcançado. 
Nesse ponto, deve o Poder Público intervir para direcionar adequadamente os investimentos empresariais para as finalidades previstas no plano diretor municipal e na lei específica que institui a operação consorciada.

A partir da implementação das operações consorciadas, o Município poderá emitir quantidades determinadas de certificados de potencial adicional de construção, que serão alienados em leilão ou utilizados no pagamento das obras da própria operação, assim expressa o art. 34, caput, do Estatuto da Cidade. Com tais certificados, os proprietários poderão ter o direito de construir acima do coeficiente permitido, porém, esse direito valerá somente nas áreasobjeto da operação.

Como qualquer outra atividade realizada em modelo de cooperação, os direitos e as obrigações serão compartilhados, não haverá apenas benefícios aos entes particulares em relação à regularização fundiária, ou à obtenção de licenças especiais para construir além do coeficiente legal máximo.

Um dos requisitos mínimos que deverá constar no plano de ação das operações é a contrapartida exigida dos particulares de cunho financeiro. Os recursos arrecadados pelo Poder Público Municipal serão destinados, exclusivamente, à realização das ações estabelecidas no próprio plano de operação urbana consorciada.

Segundo o art. 32, $\S 1^{\circ}$, parte final, do Estatuto da Cidade, são objetivos das operações urbanísticas consorciadas: a) transformações urbanísticas estruturais; b) melhorais sociais; c) valorização ambiental.

Nas transformações urbanísticas estruturais se pretende rever os elementos de infraestrutura urbana para a melhoria do bem-estar dos moradores e usuários permanentes, através do calçamento das ruas, da construção de espaços para o escoamento e capitação da água pluvial, sinalização adequada das vias, limpeza dos terrenos abandonados, entre outros.

As melhorias sociais pautam-se, além de transformações estruturais necessárias, na implantação de postos de saúde, escolas, espaços comunitários para lazer, esportes, eventos, reuniões do bairro, na construção de centros habitacionais, na fomentação do comércio, etc. O terceiro objetivo do instituto é a valorização ambiental, que não se satisfaz apenas com a preservação do ambiente natural; este é um dos elementos do conceito de meio ambiente, formando ainda pelo ambiente artificial e pelo ambiente cultural.

Dessa forma, a valorização expressa no instituto o revela como meio de preservação do ambiente em todas as suas dimensões: natural, social, econômica, cultural; buscando dar efetividade a um dos preceitos expressos na Constituição, em matéria urbanística, a garantia do bem-estar dos habitantes da cidade. 
No que tange a esse último aspecto, as operações urbanas consorciadas são também instrumentos mais democráticos, pois possibilitam a participação dos próprios habitantes da cidade na resolução dos problemas urbanos que lhes diminuem a qualidade de vida.

E pelo fato do planejamento e controle estar nas mãos do governo municipal, ente mais próximo às áreas afetadas, os cidadãos, em deliberação com os órgãos públicos responsáveis, poderão elaborar modelos de atuação que estabeleçam um equilíbrio entre as necessidades de desenvolvimento econômico da cidade, e os direitos dos habitantes, a citar alguns: o direito à vida, à saúde, à educação, à mobilidade, à segurança, à moradia, à assistência social.

\section{A AÇÃO PARTICIPATIVA EM PROL DA VALORIZAÇÃO AMBIENTAL}

Planejar, executar e gerir as políticas de desenvolvimento urbano é, em regra, dever do Poder Público, na figura dos Municípios, conforme o mandamento constitucional já citado. Entretanto, sabe-se que, na realidade, os recursos disponíveis para a concretização desses deveres são escassos, ou, quando existem, mal administrados, pelos seguintes aspectos: falta de estrutura dos órgãos municipais; falta de planejamento das ações; ausência de corpo técnico de servidores para elaborar o plano urbano; falta de apoio do Estado, da União, e dos entes da sociedade civil; entre outros fatores. Não cumpre aqui discutir o porquê de tal situação, e sim apresentar instrumentos previstos na legislação pátria, capazes de darem concretude às ações para o desenvolvimento urbano sustentável.

Salienta Odete Medauar (2004, p. 215) que, dentre os instrumentos arrolados no Estatuto da Cidade, as operações urbanas consorciadas se destacam por uma simples característica, possibilitarem o Poder Público se associar com a iniciativa privada no intuito de efetuar as melhorias urbanas desejadas pela população. E em razão dos parcos recursos públicos disponíveis, as parcerias com os entes privados, incluindo a participação comunitária, torna-se um recurso muito utilizado atualmente em várias cidades, como São Paulo ${ }^{6}$, Belo Horizonte, e Rio de Janeiro.

\footnotetext{
6 “A primeira Operação Urbana realizada em São Paulo foi a Operação Urbana Anhangabaú, aprovada pela Lei 11.090/1991, com o objetivo de revitalizar a área central da cidade” (MEDAUAR, 2004, p. 215).
}

REVISTA DO DIREITO PÚBLICO, Londrina, v.9, n.1, p.101-120, jan./abr.2014 
Os fundamentos desse modelo de ação podem ser retirados dos preceitos constitucionais que versam sobre a ordenação urbana e o meio ambiente. $\mathrm{O}$ artigo 225, ao preconizar o direito ao meio ambiente ecologicamente equilibrado, afirma que é dever do Poder Público, e da coletividade, preservá-lo e defendêlo para as presentes e futuras gerações.

O Estatuto da Cidade, instrumentalizador do art. 182 e 183 da Constituição Federal, dispõe em seu art. $2^{\circ}$, incisos II e III, respectivamente, acerca da:

II - gestão democrática por meio da participação da população e de associações representativas dos vários segmentos da comunidade na formulação, execução e acompanhamento de planos, programas e projetos de desenvolvimento urbano; III - cooperação entre os governos, a iniciativa privada e os demais setores da sociedade no processo de urbanização, em atendimento ao interesse social;

Observa-se, desse modo, que a participação ativa da sociedade civil na elaboração e execução dos planos urbanos é diretriz das políticas de desenvolvimento das cidades, e revestem as ações governamentais de um colorido democrático e pluralista, vertente primordial no Estado Democrático de Direito para a construção de uma sociedade igualitária e de acordo com os parâmetros da justiça social.

Embora, exista uma tendência histórica das políticas do Estado Brasileiro estarem direcionadas ao atendimento dos interesses das classes dominantes, o que na conjectura neoliberal, mostra-se como a prevalência dos interesses dos grandes empresários, e do mercado financeiro; a participação da sociedade civil nas operações urbanas consorciadas permite que os interesses públicos, no caso, as necessidades da comunidade afetada, prevaleçam, ou, ao menos, sejam consideradas.

Carvalho Filho destaca que a atuação participativa do Poder Municipal com os entes da sociedade civil, através dos termos de parceria, visa obter melhores resultados no desempenho dos serviços de utilidade pública. A atuação se faz possível por meio de convênios, definidos como ' 'ajustes plurilaterais em que os pactuantes cooperam mutuamente entre si buscando fins de interesses comuns a todos" (CARVALHO FILHO, 2013, p. 50).

Logo, a implementação dos convênios, nas medidas urbanísticas, viabiliza a obtenção dos resultados desejados, principalmente, quanto à valorização e proteção ambiental e à construção de um meio ambiente urbano mais saudável. 
E para Marinella Machado e Ana Luísa Nogueira (2007, p. 9), ainda representa um 'profundo aprendizado da cidadania e da democracia por uma população que se torna intérprete e coautora de suas próprias leis”’.

Os habitantes têm direito a viverem em uma cidade sustentável, como corolário do direito ao meio ambiente ecologicamente equilibrado, o que significa a harmonia e compatibilidade entre o desenvolvimento e o bem-estar. A qualidade de vida, também assegurada, é alcançada por uma conjunção de direitos transindividuais, como à saúde, à educação, ao lazer, ao trabalho, todos de natureza coletiva e merecedores de especial cuidado do Estado.

Para identificar as mazelas da urbe, que fragilizam tais direitos, e buscar corrigi-las eficazmente, não há maneira mais certa do que através dos seus próprios moradores, sujeitos interessados, e futuros beneficiados com as melhorias de ordem urbanística. Assim, expressa José dos Santos Carvalho Filho:

Se um plano urbanístico resulta apenas de pareceres técnicos elaborados em gabinetes de autoridades administrativas, as ações que dele provierem não representarão, com certeza, os anseios das comunidades. Como o alvo da política urbana é o bem-estar da população, deve esta participar, em cogestão, para as ações e estratégias adequadas. (2013, p. 48)

A atuação da sociedade civil se dá por meio da chamada gestão democrática, que representa a administração dos interesses e bens comuns a partir da participação direta ou indireta. Participação direta é quando os próprios moradores e usuários da cidade apresentam opiniões, sugestões, deliberam sobre os problemas urbanos, principalmente em audiências públicas, ou seja, se envolvem na formulação do plano urbano. Já a participação indireta é aquela no qual os moradores, da área escolhida para a intervenção urbanística, se fazem representados por associações, com a cooperação de outros entes, a exemplo de Organizações Sociais. Poderão, ainda, tais formas de participação ser de interesse geral ou de interesse específico, este albergando os interesses de um determinado segmento da sociedade, aqueles visando à proteção dos interesses da população em geral. (CARVALHO FILHO, 2013, p. 49).

A gestão democrática, por sua vez, como afirma o Carvalho Filho (2013, p. 49), combina três fases da política urbana: a formulação; a execução; e o acompanhamento. A formulação constitui-se em estudos preliminares, 
elaboração de pareceres, projeções e estratégias. Na execução, as ideias são efetivamente implementadas. E por fim, o acompanhamento, ou fiscalização das ações, observando se estão adequadas com os objetivos iniciais.

Destarte, o Estatuto da Cidade privilegia a questão ambiental, pois as ações de política urbana devem buscar a proteção ao meio ambiente, o que, inserido no contexto urbano, significa o acesso dos moradores aos direitos básicos para uma vida digna. O doutrinador José Afonso da Silva, no mesmo sentido, aduz que:

Em suma, o que está vendo é que a atividade urbanística tem um sério compromisso com a preservação do meio ambiente natural e cultural, buscando assegurar, de um lado, condições de vida respeitável e, de outro lado, a sobrevivência de legados históricos e artísticos e a salvaguarda de belezas naturais e paisagísticas de deleite do homem. (1998, p. 153)

A valorização ambiental é pressuposto para a garantia do bem-estar dos habitantes da cidade, o que requer o equilíbrio entre os interesses econômicos, sociais, políticos, estruturais, arquitetônicos. Por essa razão, a participação dos entes privados, nas intervenções urbanísticas, permite que todos os interesses relacionados aos problemas urbanos sejam sopesados em busca da satisfação da função social da cidade.

\section{CONSIDERAÇÕES FINAIS}

1) O ambiente ecologicamente equilibrado é direito fundamental de todos, consagrado pelo art. 225 da Constituição Federal de 1988. O texto constitucional compreende meio ambiente em um sentido amplo, item intrinsicamente ligado à qualidade da vida, conjugando os elementos naturais, culturais e artificiais. Estes são diretamente influenciados pelas relações urbanas e servem de parâmetro para aferição da qualidade de vida nas cidades.

2) O desenvolvimento urbano é regido pelo art. 182 da Constituição Federal, cuja execução cabe aos municípios, na forma dos Planos Diretores respectivos, que implantarão os institutos elencados no Estatuto da Cidade. Como diretrizes da legislação urbanística pátria, observa-se, dentre outras, a garantia bem-estar dos habitantes, a gestão democrática, a atuação participativa e a preservação do meio ambiente. Nesse interim, a Operação Urbana Consorciada se revela como instrumento eficaz a guiar a Política de 
Desenvolvimento Urbano dentro das balizas estabelecidas pelo art. 182 e 225 da CF/88, e efetivar o direito fundamental ao meio ambiente equilibrado no contexto da cidade.

3) Tal instituto jurídico-político, estabelecido nos art. 32 e 33 do Estatuto da Cidade, cria um modelo de formulação, execução e gerenciamento das políticas urbanas que conjugam esforços e amplia a campo de atuação do Poder Público, trazendo melhores resultados através da atuação participativa entre governo e sociedade, seja de forma direta (p.ex. audiências públicas) ou indireta (p.ex. associações de bairro). Com a proximidade do cidadão aos órgãos gestores das políticas públicas, os interesses daquele serão efetivamente compreendidos e considerados. Assim, as intervenções urbanísticas se direcionam a atender às demandas e a solucionar os problemas das comunidades.

4) A melhoria na qualidade do meio ambiente urbano perpassa por mudanças infraestruturais, sociais e pela valorização ambiental. E para alcançar esses objetivos, é importante que os habitantes da cidade compreendam que são atores fundamentais na busca da garantia dos seus próprios direitos individuais e sociais. Assim, a participação dos habitantes na execução das políticas urbanas é um exercício de cidadania, que promove a qualidade de vida e fortalece o regime democrático.

\section{REFERÊNCIAS}

BONIZZATO, Luigi. O advento do Estatuto da Cidade e as conseqüências fáticas no âmbito da propriedade, vizinhança e sociedade participativa. Rio de Janeiro: Lumen Juris, 2005.

BRASIL. Constituição da República Federativa do Brasil. Brasília, DF: Senado Federal, 1988.

BRASIL. Lei 10.257, de 10 de julho de 2001. Regulamenta os arts. 182 e 183 da Constituição Federal, estabelece diretrizes gerais da política urbana e dá outras providências. Disponível em: <https://www.planalto.gov.br > . Acesso em: 01 ago. 2013.

CARVALHO FILHO, José dos Santos. Comentários ao estatuto da cidade. 5. ed. São Paulo: Atlas, 2013. 
MEDAUAR, Odete; ALMEIDA, Fernando Dias Menezes de (coord.). Estatuto da Cidade: Lei 10.257, de 10.07.2001, comentários. 2. ed. São Paulo: Revista dos Tribunais, 2004.

MELLO, Celso Antônio Bandeira de. Curso de Direito Administrativo. 28. ed. São Paulo: Malheiros, 2011.

MEIRELLES, Hely Lopes. Direito de Construir. 9. ed. São Paulo: Malheiros, 2005.

MOREIRA, Ana Luísa Nogueira; ARAÚJO, Marinella Machado.

Operações Urbanas Consorciadas no Estatuto da Cidade. Anais do XVI do Congresso Nacional do CONPEDI. 2007. Disponível em: $<\underline{\text { http:// }}$ conpedi.org.br/ >. Acesso em: 02 abr. 2013.

SILVA, José Afonso. Curso de Direito Constitucional Positivo. 17. ed. São Paulo: Malheiros, 2000. Direito Ambiental Constitucional. 2. ed. São Paulo: Malheiros, 1998.

VARELLA, Marcelo Dias. Direito Internacional Econômico Ambiental. Belo Horizonte: Del Rey, 2003.

Artigo recebido em: 31/08/2013 Aprovado para publicação em: 01/04/2014

Como citar: MAGANHINI, Thaís Bernardes. MARTINS, Pablo Oliveira. As operações urbanas consorciadas como instrumento de promoção do meio ambiente urbano saudável. Revista do Direito Público. Londrina, v.9, n.1, p.101-120, jan./abr.2014. DOI: 10.5433/1980-511X.2014 v9n1p101. 